\title{
Femur Properties of Embryo in the Layer Hybrid and Pure Breeds
}

\section{-Author(s)}

Onbaşılar EE' (iD https://orcid.org/0000-0002-1321-0280 Güngör ÖF' (DD https://orcid.org/0000-0002-7273-7242 Demir T" (iD) https://orcid.org/0000-0001-6352-8302 Elibol Erbay FK"I (iD https://orcid.org/0000-0002-4117-1098 Kahraman M' (DD https://orcid.org/0000-0002-7757-2483 Taban S Iv (D) https://orcid.org/0000-0002-7997-9412 Çalık $A^{v} \quad$ (iD) https://orcid.org/0000-0003-4550-9321 Pirpanahi Mv (iD https://orcid.org/0000-0002-8137-9811

Department of Animal Breeding and Husbandry, Faculty of Veterinary Medicine, Ankara University, Ankara, 06110, Turkey.

Department of Mechanical Engineering, TOBB University of Economics and Technology, Ankara, 06560, Turkey.

III Department of Micro and Nanotechnology, TOBB University of Economics and Technology, Ankara, 06560, Turkey.

Department of Soil Science and Plant Nutrition, Faculty of Agriculture, Ankara University, Ankara, Turkey 06110, Turkey.

Department of Animal Nutrition \& Nutritional Diseases, Faculty of Veterinary Medicine, Ankara University, Ankara 06110, Turkey.

\section{Mail Address}

Corresponding author e-mail address E. E. Onbaşılar

Department of Animal Breeding and Husbandry, Faculty of Veterinary Medicine, Ankara University, Ankara - 06110 Turkey.

Phone: +90 3123170315

Email: onbasilar@ankara.edu.tr

\section{- Keywords}

Layer, pure breed, hybrid, embryo, femur.

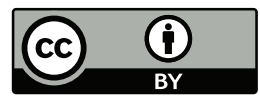

Submitted: 20/March/2018

Approved: 10/September/2018

\section{ABSTRACT}

Layer hybrids are more superior in the egg yield than pure breeds. But this superiority causes some problems in the bones during the production period. There are a lot of differences among genotypes in the production period that have been examined extensively, however, the differences throughout incubation period aren't known yet. Thus, the objective of this study was to evaluate the differences in femur properties of pure breed and layer hybrid embryos during the incubation period. A total of 354 fresh hatching eggs were used from one hybrid (Lohman White) and two pure breeds (Denizli \& Gerze). The eggs were incubated. Hatching eggs from each genotype at the beginning of embryonic days (E) 19 and E21 were examined. At these embryonic ages, 12 eggs were selected from each genotype. The eggs were opened and embryos were sacrificed by cervical dislocation. Both femurs were dissected from each embryo and then structure, mineral composition and mechanical properties of femur were determined. The genotype affected the length, width and Zn level in the femur of embryos. Weight, length, width, load of yield and ultimate, ash and all examined minerals increased with embryonic development. These results showed that some femur properties of embryos were influenced by the genotype and layer hybrid embryos are beginning to be advantageous in terms of $\mathrm{Zn}$ level in the femur at E21. This study leads to better understanding femur development during the incubation period in layer hybrid and pure breeds.

\section{INTRODUCTION}

Skeleton is a basic support of poultry. It provides support to the body, movement and an important Ca storage for the formation of the eggshell during the low dietary Ca supply in layer hens (Kover et al., 2004). Leg problems have very high incidence in the poultry sector and cause economic and welfare problems (Cook, 2000). Leg problems are expected to reduce production and they can affect the osteoporosis, lameness, bone fracture, walking ability, and reduce access to feed and water (Angel, 2007; Nääs et al., 2009; Webster, 2004). Because of these problems, it is important to diminish the leg problems in poultry.

Leg problems may occur in the pre and post hatch period. Incubation conditions have a significant effect on bone characteristics and leg problems of poultry (Groves \& Murin, 2014; Oviedo-Randon et al., 2009; Van der Pol et al., 2014). Bone mineralization and development begin during embryo development, so it is possible for skeletal disorders to develop when the embryo is developing in the egg (Torres \& Korver, 2018). Growth of long bones is through endochondral ossification in the embryo (Van der Eerden et al., 2003). The deposition of minerals to the different egg compartments is very important for optimal embryonic 
Onbaşılar EE, Güngör ÖF, Demir T, Elibol Erbay FK, Kahraman M, Taban S, Çalık A, Pirpanahi M
Femur Properties of Embryo in the Layer Hybrid and Pure Breeds development because minerals are vital for the development of the skeletal systems (Oviedo-Randon et al., 2009). Zn is an important element to support the development of bone (Sahraei et al., 2012).

Genetic selection and improvements in management and nutrition have led to dramatic increases in potential for growth and egg production in laying hens (Kover et al., 2004). Embryos of current hybrids have a high metabolic rate (Tona et al., 2004). Laying hens are typically the most sensitive type of poultry to perturbations in Ca metabolism and subsequently skeletal disease. Many of the production expectations placed on modern poultry put the bird at risk for diseases of the skeletal system (Kover et al., 2004). In view of the foregoing, we hypothesized that genetic selection may affect the bone structure, mineral composition and mechanical properties during the embryonic period. Therefore, this study sheds light on femur differences in pure breed (Denizli \& Gerze, local Turkish breeds) and layer hybrid (Lohman White) during incubation.

\section{MATERIALS AND METHODS}

This study was approved by Ankara University Animal Care and Use Committee (2015/5/101). A total of 354 hatching eggs were collected from 3 different layer breeder genotypes (Denizli, Gerze \& Lohman White) at 29 weeks of age on the same day. All eggs were numbered and incubated for 18 days at $37.7^{\circ} \mathrm{C}$, $53 \%$ RH (Çimuka Incubator, Ankara, Turkey). On day 18, all eggs were transferred to the hatcher (Çimuka Incubator, Ankara, Turkey) at $37.5^{\circ} \mathrm{C}$ and $70 \% \mathrm{RH}$ (Onbaşılar et. al., 2017). Twelve eggs from each genotype were selected on the beginning E19 and E21. The eggs were opened, and embryos were sacrificed by cervical dislocation. Both femur were dissected from each embryo. The femur was cleaned of all soft tissues. The bones were weighed. Femur length was measured from the Trochanter major to Condylus lateralis and the width at the medial diaphysis (Alfanso-Torres et al., 2009). And they were stored at $-20^{\circ} \mathrm{C}$ for further analyses.

Dry matter and ash in the femur were determined according to the AOAC (2000). Mineral levels (Zn, Cu, $\mathrm{Mn}, \mathrm{Fe}, \mathrm{Na}, \mathrm{K}, \mathrm{Ca}$ and $\mathrm{Mg}$ ) from femur samples were analyzed using an ICP-OES (Perkin Elmer Optima ${ }^{\mathrm{TM}}$ DV 2100 Model, Dual View, Perkin Elmer Life and Analytical Sciences, Shelton, CT, USA) (Boss et al., 2004). Femurs were subjected to the three point bending tests until failure occurred, tests were performed on
Instron 5944 testing frame (Instron, Norwood, MA, USA). Loading rate was $5 \mathrm{~mm} / \mathrm{min}$. Spon lenght (L) was $10 \mathrm{~mm}$ for femurs. Load was applied the mid point of the shaft. Load vs displacement data was collected for each sample. Stiffness values were calculated from the slope of linear region of the load displacement curves. Ultimate load and displacement at ultimate load were determined from the load displacement curves as well. Yield load is the load which permanent deformation of the system begins. Displacement at yield load is the displacement at which permanent deformation begins.

\section{Statistical analysis}

Data were tested for distribution normality and homogeneity of variance. Two-way ANOVA was used to determine the differences between genotype and period. Tukey test was used when a significant difference was found among groups for posthoc multiple comparisons with SPSS for Windows (IBM Corp, 2013). Statistical significance was taken as $p \leq 0.05$ (Dawson \& Trapp, 2001).

\section{RESULTS}

Femur properties of embryos are shown in Table 1, 2 and 3. Statistically significant genotype effects on the weight and mechanical properties of the femur in the incubation period weren't observed. However length $(p<0.001)$ and width $(p<0.01)$ of the femur in embryos were affected by the genotype. Length and width of femur were 20.52 and $1.55 \mathrm{~mm}, 18.81$ and $1.38 \mathrm{~mm}, 17.68$ and $1.38 \mathrm{~mm}$ for LW, Denizli \& Gerze embryos, respectively.

Embryonic age had influence on weight, length, width and mechanical properties except for displacement at ultimate load. Weight, length and width of femur increased with embryonic growth. Weight was 0.17 and $0.21 \mathrm{~g}$, length was 18.32 and $19.68 \mathrm{~mm}$, width was 1.32 and $1.54 \mathrm{~mm}$, stiffness was 4.27 and $9.51 \mathrm{~N} / \mathrm{mm}$, yield load was 2.57 and 4.49 $\mathrm{N}$, displacement at yield load was 0.53 and $0.38 \mathrm{~mm}$ and ultimate load was 3.55 and $6.09 \mathrm{~N}$ in the E19 and E21, respectively.

Only $\mathrm{Zn}$ level in the femur was affected by the genotype and the highest $\mathrm{Zn}$ level was found in the femur of LW embryos. Zn level was 390.46, 314.75 and $337.16 \mathrm{mg} / \mathrm{kg}$ DM in LW, Denizli and Gerze embryos, respectively. All examined minerals in the femur increased with embryonic age. Genotype and embryonic age interaction was found in the $\mathrm{Cu}$ and $\mathrm{Zn}$ levels of the femur. 
Onbaşılar EE, Güngör ÖF, Demir T, Elibol Erbay FK, Kahraman M, Taban S, Çalık A, Pirpanahi M

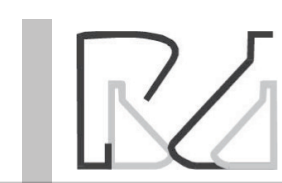

Femur Properties of Embryo in the Layer Hybrid and Pure Breeds
Table 1 - Effect of genotype and embryonic age on weight, length and width of femur.

\begin{tabular}{|c|c|c|c|c|}
\hline \multirow{2}{*}{\multicolumn{2}{|c|}{ Genotype }} & Weight (g) & Length $(\mathrm{mm})$ & Width (mm) \\
\hline & & & & \\
\hline \multicolumn{2}{|c|}{ Lohman White } & 0.20 & $20.52^{\mathrm{a}}$ & $1.55^{a}$ \\
\hline \multicolumn{2}{|c|}{ Denizli } & 0.19 & $18.81^{b}$ & $1.38^{\mathrm{b}}$ \\
\hline \multicolumn{2}{|l|}{ Gerze } & 0.18 & $17.68^{b}$ & $1.38^{\mathrm{b}}$ \\
\hline \multicolumn{5}{|c|}{ Embryonic age } \\
\hline \multicolumn{2}{|c|}{ E19 } & 0.17 & 18.32 & 1.32 \\
\hline \multicolumn{2}{|l|}{ E21 } & 0.21 & 19.68 & 1.54 \\
\hline \multirow{2}{*}{$\begin{array}{l}\text { Lohman } \\
\text { White }\end{array}$} & E19 & 0.17 & 19.95 & 1.49 \\
\hline & E21 & 0.22 & 21.08 & 1.61 \\
\hline \multirow[t]{2}{*}{ Denizli } & E19 & 0.17 & 17.69 & 1.24 \\
\hline & E21 & 0.22 & 19.93 & 1.51 \\
\hline \multirow[t]{2}{*}{ Gerze } & E19 & 0.17 & 17.32 & 1.24 \\
\hline & E21 & 0.19 & 18.04 & 1.51 \\
\hline \multicolumn{2}{|c|}{ SEM } & 0.004 & 0.196 & 0.020 \\
\hline \multicolumn{2}{|c|}{ Genotype* } & NS & $<0.001$ & 0.001 \\
\hline \multicolumn{2}{|c|}{ Embryonic age* } & $<0.001$ & 0.001 & $<0.001$ \\
\hline \multicolumn{2}{|c|}{ GenotypeXEmbryonic age* } & NS & NS & NS \\
\hline
\end{tabular}

a,bMeans within a column with different superscript letters differ. NS: Non significant.

${ }^{*}$ Comparisons between genotype and embryonic age groups based on a two way ANOVA.

\section{DISCUSSION}

The development of the skeletal system and its properties at the embryonic growth are important for the production period. Femur of LW embryos selected for high egg production were longer and wider than that of pure breeds' embryos when examined both embryonic days. This result showed that genetic selection for layers has led to increases in femur length and width in the embryonic development. Femur of LW may be more fragile because the bone weight does not change despite the increase in bone length and width during the incubation. And this was a disadvantage for LW at hatch and at a later period.

The bone expands and extends under the compressive loads. Stiffness is the resistance of an elastic body to deform. Elastic deformation is reversible and the bone returns to its original shape when the load is removed (Forester-Zhang \& Bishop, 2017). Stiffness and ultimate load were highest in the embryos of LW but these values are not statistically significant. And this showed that femur of LW embryos was more fragile under compression than the pure breeds. This is a negative situation for hybrid welfare. Sevil-Kilimci \& Kara (2013) reported that bones with higher stiffness values are considered more fragile, even though the breaking points are similar, because the amount of deformation is less.

Weight, length, stiffness, ultimate load and yield load of femur bones in embryos increased $(p<0.01)$ and displacement at yield load was decreased $(p<0.05)$ from E19 to E21 due to the embryonic development. One of the key properties of bone strength is growth, because bone mass increases with growth (Frost, 1997). There are limited results on the age-related changes in bone parameters of laying hen embryos. Displacement at ultimate load of bones didn't change from E19 to E21. Genotype and embryonic age interaction was

Table 2 - Effect of genotype and embryonic age on mechanical properties of femur.

\begin{tabular}{|c|c|c|c|c|c|c|}
\hline & & $\begin{array}{l}\text { Stiffness } \\
(\mathrm{N} / \mathrm{mm})\end{array}$ & $\begin{array}{l}\text { Yield load } \\
(\mathrm{N})\end{array}$ & $\begin{array}{l}\text { Displacement at yield load } \\
(\mathrm{mm})\end{array}$ & $\begin{array}{l}\text { Ultimate Load } \\
(\mathrm{N})\end{array}$ & $\begin{array}{c}\text { Displacement at ultimate } \\
\text { load }(\mathrm{mm})\end{array}$ \\
\hline \multicolumn{7}{|l|}{ Genotype } \\
\hline \multicolumn{2}{|l|}{ Lohman White } & 7.06 & 3.48 & 0.38 & 5.10 & 1.14 \\
\hline \multicolumn{2}{|l|}{ Denizli } & 6.78 & 3.50 & 0.52 & 4.64 & 1.24 \\
\hline \multicolumn{2}{|l|}{ Gerze } & 6.82 & 3.60 & 0.47 & 4.72 & 1.16 \\
\hline \multicolumn{7}{|l|}{ Embryonic age } \\
\hline \multicolumn{2}{|l|}{ E19 } & 4.27 & 2.57 & 0.53 & 3.55 & 1.21 \\
\hline \multicolumn{2}{|l|}{ E21 } & 9.51 & 4.49 & 0.38 & 6.09 & 1.14 \\
\hline \multirow[t]{2}{*}{ Lohman White } & E19 & 4.70 & 2.72 & 0.39 & 3.67 & 1.07 \\
\hline & E21 & 9.43 & 4.25 & 0.37 & 6.54 & 1.20 \\
\hline \multirow[t]{2}{*}{ Denizli } & E19 & 3.84 & 2.62 & 0.61 & 3.68 & 1.48 \\
\hline & E21 & 9.72 & 4.39 & 0.42 & 5.59 & 1.00 \\
\hline \multirow[t]{2}{*}{ Gerze } & E19 & 4.26 & 2.38 & 0.60 & 3.30 & 1.01 \\
\hline & E21 & 9.38 & 4.82 & 0.34 & 6.13 & 1.23 \\
\hline \multicolumn{2}{|l|}{ SEM } & 0.308 & 0.109 & 0.036 & 0.137 & 0.074 \\
\hline \multicolumn{7}{|l|}{$p$-value* } \\
\hline \multicolumn{2}{|l|}{ Genotype } & NS & NS & NS & NS & NS \\
\hline \multicolumn{2}{|c|}{ Embryonic age } & $<0.001$ & $<0.001$ & 0.032 & $<0.001$ & NS \\
\hline \multicolumn{2}{|c|}{ GenotypeXEmbryonic age } & NS & NS & NS & NS & NS \\
\hline
\end{tabular}

NS: Non significant.

${ }^{*}$ Comparisons between genotype and embryonic age groups based on a two way ANOVA. 
Onbaşılar EE, Güngör ÖF, Demir T, Elibol Erbay FK, Kahraman M, Taban S, Çalık A, Pirpanahi M
Femur Properties of Embryo in the Layer Hybrid and Pure Breeds not statistically significant for those bone parameters. Alfonso-Torres et al. (2009) showed that there weren't found any significant interaction between incubation day and breeder age on weight and length of femur. They also reported that weight and width of bones in broiler embryos were affected by breeder age.

To maximize egg production, genetic selection may have inadequate structural bone mass, leading to increased bone fragility and thus bone fractures of laying hens during the production period (Budgell \& Silversides, 2004). Embryos supply the mineral from the shell, albumen and yolk of egg during the incubation period. During the embryonic development, skeletal structure forms the basis. Strong skeletal development in the embryonic period affects the welfare and production of laying hens during the posthatch period. Especially, mineral composition of bone is important. Each examined mineral has a different role in the development of the embryo. Bone Zn will concentrate in the osteoid layer before calcification corresponding to the most intense of alkaline phosphatase (Humont, 1961). Cu deficiency inhibits bone growth and supports the characteristic of osteoporosis. Defects and fragility increase in bones and cartilages occurs as a result of Cu deficiency (Bridges and Moffitt, 1990). Skeletal abnormalities are found in animals lacking $\mathrm{Mn}$, including chondrodystrophy in chick embryos (Beatile \& Avenell, 1992). In our study ash, Cu, Fe, Mn, $\mathrm{Na}, \mathrm{Ca}, \mathrm{P}, \mathrm{Mg}, \mathrm{K}$ in the femur of embryos were not affected by the genotype. Only $\mathrm{Zn}$ level in the femur of examined embryos was different $(p<0.01)$. Kidd et al. (1992) showed an increase in the tibia weight when breeders were fed organic Zn. Therefore, their result indicated that $\mathrm{Zn}$ was linked to long bone weight. A component of carbonic anhydrase, Zn plays regulatory roles in bone development (Kidd et al., 1992; Kienholz et al., 1964). And this increase may lead to length and weight of femur in the embryonic development. Rayan et al. (2010) reported that the percentage of $\mathrm{Ca}$ in tibia bone wasn't significantly affected by strain, breeder age and their interaction. In femur bones, the ash content was highest in LW embryos but this was not statistically significant.

Ash and mineral contents increased considerably from E19 to E21 in all examined embryos. However, the increase in $\mathrm{Ca}$ and $\mathrm{P}$ levels was lower than in other minerals from E19 to E21. Similarly, Yair et al. (2012) showed that increased mineral contents with embryonic development. Genotype and embryonic age interaction was important only regarding $\mathrm{Cu}$ and $\mathrm{Zn}$ levels of femur. This interaction was the source of

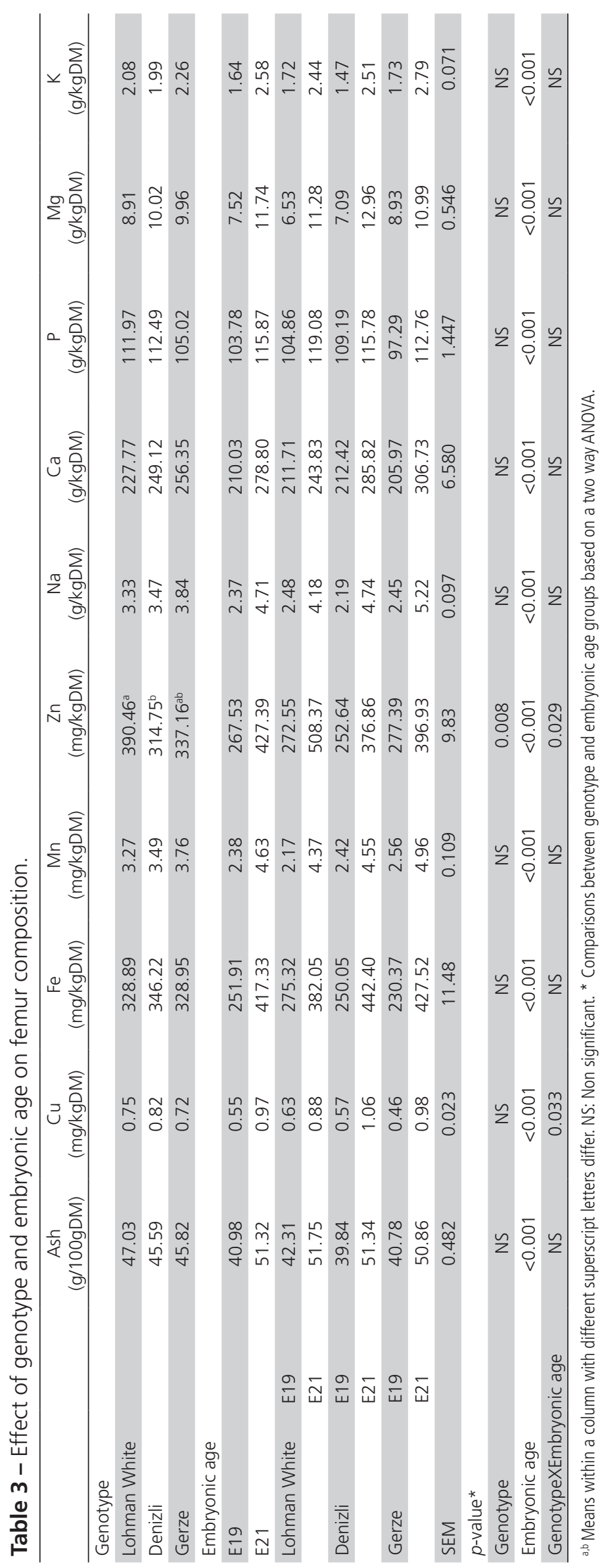


Onbaşılar EE, Güngör ÖF, Demir T, Elibol Erbay FK, Kahraman M, Taban S, Çalık A, Pirpanahi M
Femur Properties of Embryo in the Layer Hybrid and Pure Breeds the increase in Cu level of femur was lower and in $\mathrm{Zn}$ level of femur was higher for the LW embryos than those in the pure breeds from E19 to E21.

\section{CONCLUSION}

Based on the results obtained, layer genotype doesn't statistically affect the bone mechanical properties of femur. As the embryonic age increased, the examined femur properties increased, except for the displacement at ultimate load value. Genotype and embryonic age interaction is important for $\mathrm{Cu}$ and $\mathrm{Zn}$ femur values. These results showed that layer hybrid embryos are beginning to be advantageous at the hatch due to the $\mathrm{Zn}$ content of the femur.

\section{ACKNOWLEDGMENTS}

This study was supported by TÜBITAK Fund (Project No: 1150920).

\section{REFERENCES}

Alfonso-Torres KA, Gargaglioni LH, Pizauro JM, Faria Filho DE, Furlan $\mathrm{RL}$ and Macari M. Breeder age and bone development in broiler chicken embryos. Brazilian Journal of Veterinary and Animal Science 2009;61:219-226.

Angel R. Metabolic disorders: limitations to growth of and mineral deposition into the broiler skeleton after hatch and potential implications for leg problems. Journal of Applied Poultry Research 2007;16:138-149.

AOAC - Association of Official Analytical Chemists. Official methods of analysis of AOAC international. 17th ed. Gaithersburg; 2000.

Boss CB, Fredeen KJ. Concepts, instrumentation and techniques in inductively coupled plasma optical emission spectrometry. Shelton; 2004.

Bridges $\mathrm{CH}$, Moffitt PG. Influence of variable content of dietary zinc on copper metabolism of weanling foals. American Journal of Veterinary Research 1990;51:275-280.

Budgell KL, Silversides FG. Bone breakage in three strains of end-of-lay hens. Canadian Journal of Animal Science 2004;84:745-747.

Cook ME. Skeletal deformities and their causes: introduction. Poultry Science 2000;79:982-984.

Dawson B, Trapp RG. Basic and clinical biostatistics. $3^{\text {rd }}$ ed. New York: Lange Medical Books-McGraw-Hill; 2001

Frost HM. On our age related bone loss: insights from a new paradigm. Journal of Bone and Mineral Research 1997;12:1539-1546.

Forestier-Zhang L, Bishop N. Bone strength in children: understanding basic bone biomechanics. Archives of Disease in Childhood-Education and Practice 2016;101:2-7.

Groves PJ, Muir WI. A meta-analysis of experiments linking incubation conditions with subsequent leg weakness in broiler chickens. PlosOne 2014;9:e102682.
Haumont S. Distribution of zinc in bone tissue. Journal of Histochemistry and Cytochemistry 1961;9:141-145.

IBM Corporation. IBM SPSS statistics for windows. Version 22.0. Amonk; 2013.

Kidd MT, Anthony NB, Lee SR. Progeny performance when dams and chicks are fed supplemental zinc. Poultry Science 1992;71:1201-1206.

Kienholz EW, Sunde ML, Hoekstra WG. Influences of dietary zinc, calcium and vitamin $D$ for hens on zinc content of tissues and eggs and on bone composition. Poultry Science 1964;43:667-675.

Korver DR, Saunders-Blades JL, Nadeau KL. Assessing bone mineral density in vivo: Quantitative computed tomography. Poultry Science 2004;83:222-229.

Nääs IA, Paz ICD, Baracho MS, Menezes AG, Bueno LGF, Almeida ICL, et al. Impact of lameness on broiler well-being. Journal of Applied Poultry Research 2009;18:432-439.

Onbaşılar EE, Kahraman M, Ahlat O, Güngör ÖF, Çalik A, Taban S, et al. Differences in egg nutrient availability and embryo development in white layer breeder genotypes. Poultry Science 2017;96:3600-3607.

Oviedo-Rondón EO, Wineland MJ, Funderburk S, Small J, Cutchin H, Mann M. Incubation conditions affect leg health in large, high-yield broilers. Journal of Applied Poultry Research 2009;18:640-646.

Rath NC, Huff GR, Huff WE, Balog JM. Factors regulating bone maturity and strength in poultry. Poultry Science 2000;79:1024-1032.

Rayan GN, Galal A, Fathi MM, El-Attar AH. Impact of layer breeder flock age and strain on mechanical and ultrastructural properties of eggshell in chicken. International Journal of Poultry Science 2010;9:139-147.

Sahraei M, Janmmohamdi H, Taghizadeh A, Cheraghi S. Effect of different zinc sources on tibia bone morphology and ash content of broiler chickens. Advances in Biological Research 2012;6:128-132.

Sevil Kilimci F, Kara ME. Kemiklerin mekanik özelliklerin değerlendirilmesinde kullanılan temel biyomekanik kavramlar. Animal Health, Production and Hygiene 2013;2:235-239.

Tona K, Onagbesan OM, Jego Y, Kamers B, Decuypere E, Bruggeman V. Comparison of embryo physiological parameters during incubation, chick quality, and growth performance of three lines of broiler breeders differing in genetic composition and growth rate. Poultry Science 2004;83, 507-513.

Torres CA, Korver DR. Influences of trace mineral nutrition and maternal flock age on broiler embryo bone development. Poultry Science 2018;97:2996-3003.

Van der Eerden BCJ, Karperien M, Wit JM. Systemic and local regulation of the growth plate. Endocrine Reviews 2003;24:782-801.

Van der Pol CW, Van Roovert-Reijink IAM, Maatjens CM, Van den Anker I, Kemp B, Van den Brand $\mathrm{H}$. Effect of eggshell temperature throughout incubation on broiler hatchling leg bone development. Poultry Science 2014;93:2878-2883.

Webster AB. Welfare implications of avian osteoporosis. Poultry Science 2004;83:184-192.

Yair R, Uni Z, Shahar R. Bone characteristics of late-term embryonic and hatchling broilers: Bone development under extreme growth rate. Poultry Science 2012;91:2614-2620. 
